\title{
A STRATEGY FOR DETERMINING THE CHEMICAL COMPOSITION OF RICE STRAW
}

\author{
MAHESHANI P. A. NANAYAKKARA, WALAGEDARA G.A. PABASARA, \\ ADIKARI M.P.B. SAMARASEKARA, DON A.S. AMARASINGHE* and \\ LALEEN KARUNANAYAKE** \\ "Department of Materials Science and Engineering, University of Moratuwa, Katubedda, \\ Moratuwa 10400, Sri Lanka \\ *** Department of Polymer Science, University of Sri Jayewardenepura, Nugegoda 10250, Sri Lanka \\ $\checkmark$ Corresponding author: A.M.P.B. Samarasekara, banduamp@gmail.com
}

Received May 17, 2020

As rice is the staple food of most Asian countries, rice straw has become one of the largest agricultural wastes in Asia. It has not been subjected to adequate value additions yet. However, it has excellent potential to be converted to valuable materials, as it contains a significant amount of cellulose. Therefore, it would be beneficial in many ways to identify the cellulose yields of straws of different rice varieties. In general, the cellulose content of biomass is determined by wet chemical methods. Though these methods are accurate, they are not convenient to use under industrial conditions. This research work focuses on investigating the potential of thermal analysis as an alternative way to predict cellulose yields. For the study, rice straws of most frequently cultivated traditional Sri Lankan rice varieties: Suwandel and Raththal, as well as technically modified Sri Lankan rice varieties: BG300 and BG352, were selected. The results obtained by the proposed method were validated by an established three-step chemical extraction process.

Keywords: rice straw, cellulose yield, thermal analysis, agricultural industry

\section{INTRODUCTION}

Rice is the staple food in many Asian countries. Asian paddy fields account for over $90 \%$ of the total global rice cultivation area and that caters to one-half of the world's population. ${ }^{1,2}$ Consequently, rice cultivation produces large amounts of agro-waste. Among them, the highest percentage is occupied by rice straw. According to the National Engineering Research and Development Centre of Sri Lanka, 800 GT of rice straw was produced in Sri Lanka in 2018. ${ }^{3,4}$ In most cases, the rice straw is either left in the field as uncollected or subjected to open field burning. In 2019, several cities of India experienced a smog that originated from the burning of crop waste, including rice and wheat straw. It might affect nearby countries like Sri Lanka as well. ${ }^{5,6}$ It has been reported that toxic emissions from the burning of rice straw result in air pollution, water pollution, soil degradation, and contribute to global warming. Most of these factors ultimately affect human health. Thus, it is high time to find better uses for this large agricultural waste. ${ }^{7}$
Rice straw is lignocellulose biomass that mainly consists of cell wall polymers: lignin, hemicelluloses, and cellulose ${ }^{8-10}$ Cellulose is known as the most abundant natural biopolymer on earth. It can be used as an excellent engineering material in a wide variety of high demand applications, such as the production of bio-composites, food packaging films, papers, and paperboards, etc. Further, rice straw is the most abundant source of cellulose out of all agricultural wastes, with approximately $32-47 \%$ cellulose content. Hence, the extraction of cellulose could be the right way of adding value to this agrowaste material. Nonetheless, it is vital to estimate the cellulose content of different rice straw varieties to find the types of rice straw that are capable of providing higher cellulose yields. ${ }^{10-20}$

Conventionally, the cellulose content of biomass is determined by wet chemical methods, which involve fractionation of biomass samples and further isolation of purified fractions, followed by quantification using conventional 
analytical instruments. ${ }^{21}$ Although these methods are accurate and robust, they cannot be used for industrial purposes, as they are costly and timeconsuming. Therefore, the focus of this research work has been to utilize thermo-analytical methods and mathematical tools to find out the cellulose content of rice straw as a cost-effective method.

Thermogravimetric analysis (TGA) is a useful tool of quantitative analysis in evaluating compositions of mixtures, especially when the constituents' characteristic thermal decomposition temperature profiles are well separated. ${ }^{22}$ However, the accuracy of results is questionable when a material has parallel chemical reactions and constituents with identical mass loss temperature profiles. The chemical composition of rice straw comprises, on average, 30-45\% cellulose, $20-25 \%$ hemicelluloses, $15-20 \%$ lignin, and a number of minor organic and inorganic compounds. It has been reported that some of these constituents' mass temperature profiles are overlapping. Hence, in this study, we investigate a novel thermal analysis technique by introducing modifications to existing techniques, such as the TGA method, to obtain the cellulose composition of straws of different rice varieties.

The accuracy of the above technique was verified by isolating cellulose from the same rice straw varieties through the chemical purification processes mentioned in the literature. ${ }^{23,24}$ Since there have been hardly any studies on evaluating and analysing the yields of cellulose from rice straws of various rice varieties, the method was used to evaluate the cellulose content of straws of several varieties of rice grown in Sri Lanka.

For this study, two traditional Sri Lankan rice varieties, Suwandel and Raththal, together with two technically modified varieties, BG300 and BG352, were chosen. The BG varieties are hybrids with some favorable characteristics that the traditional rice varieties lack, such as higher yield potential, improved resistance to pest and disease, etc. ${ }^{25}$ The chosen traditional rice varieties are cultivated according to conventional methods, while the hybrid $\mathrm{BG}$ rice varieties are grown using modern techniques. It is important to notice that there is a significant variation in agronomic, soil, and climatic conditions under which traditional and hybrid varieties are cultivated. ${ }^{26}$ Therefore, it is expected to obtain significant differences in the cellulose contents of their straw.

\section{EXPERIMENTAL}

\section{Rice straw materials and chemicals}

Two types of rice straws, namely, technically modified and traditional rice varieties were selected for this analysis. They were obtained from local sources. The straws of technically modified rice verities: BG300 and BG352 were collected at maturity after harvesting in the 2016 Yala season (from May to end of August) from the Rice Research Center, Batalegoda, Kurunegala, Sri Lanka. The straws of the Raththal variety were gathered at maturity after harvesting in the 2016 Yala season from the Hela Suwaya paddy cultivation area, Padaviya, Anuradhapura, Sri Lanka. Finally, rice straws of Suwandel were obtained at maturity after harvesting in 2016 Yala season from a traditional paddy cultivation area, Kurunegala, Sri Lanka. The main chemicals used for cellulose extraction were toluene $\left(\mathrm{C}_{6} \mathrm{H}_{5} \mathrm{CH} 3, \geq 99.7 \%\right.$, ACS $)$, acetic acid $\left(\mathrm{CH}_{3} \mathrm{COOH}, \geq 99.8 \%\right.$, ACS $)$ and sulfuric acid $\left(\mathrm{H}_{2} \mathrm{SO}_{4}, 95.0-97.0 \%\right.$, ACS). They were supplied by Sigma-Aldrich. Ethanol $\left(\mathrm{H}_{3} \mathrm{CCH}_{2} \mathrm{OH}\right.$, Min. $99.85 \%$, ACS), hydrogen peroxide $\left(\mathrm{H}_{2} \mathrm{O}_{2}, 50 \%\right.$ (w/v), $\mathrm{AR})$ and potassium hydroxide $(\mathrm{KOH}, \geq 85.0 \%$, GR) were purchased from VWR Chemicals, Glorchem, and MERCK Chemicals, respectively.

\section{Method of cellulose extraction}

The details of the wet-chemical methods employed in isolating cellulose from rice straw are described in our previous research publications. ${ }^{11,27,28}$ Approximately $200 \mathrm{~g}$ of rice straw from each variety was used for this extraction procedure. As an initial step, all foreign matter was sorted and removed from the rice straw. Then, dirt and water-soluble substances in the rice straws were removed by washing with warm distilled water. Air drying was carried out at room temperature for forty-eight hours, followed by oven drying at $60{ }^{\circ} \mathrm{C}$ for five hours to remove the moisture in the rice straw (Memmert $\mathrm{GmbH}$, Germany). Then, the purified and dried rice straw was powdered by an Easy Blend grinding machine. After that, ground rice straw powder was subjected to a sieving process, with the use of $250 \mu \mathrm{m}, 150 \mu \mathrm{m}, 106 \mu \mathrm{m}, 75 \mu \mathrm{m}$ and $53 \mu \mathrm{m}$ aperture sized sieves. A homogeneous blend of rice straw powder was prepared by mixing rice straw powder retained on the $150 \mu \mathrm{m}, 106 \mu \mathrm{m}, 75 \mu \mathrm{m}$ and 53 $\mu \mathrm{m}$ aperture sized sieves.

The cellulose extraction process consists of three main steps: namely, dewaxing, delignification and silica and hemicelluloses removal. Rice straw powder $(10 \mathrm{~g})$ was introduced into the Soxhlet apparatus with a $2: 1 \mathrm{v} / \mathrm{v}$ toluene/ethanol $(450 \mathrm{~mL})$ mixture and the reaction conditions were set as $400{ }^{\circ} \mathrm{C}$ temperature for 15 hours to remove wax, pigments and oils. This process was followed by oven-drying at $55^{\circ} \mathrm{C}$ for 24 hours to convert dry mass. Then, measurements related to dewaxed materials were taken. 
The dewaxed powder was subjected to the delignification process using a 3:10 v/v $\mathrm{H}_{2} \mathrm{O}_{2} / \mathrm{CH}_{3} \mathrm{COOH}$ solution with the solid:liquid ratio of $1: 60, \mathrm{~g} / \mathrm{mL}$, at $60{ }^{\circ} \mathrm{C}$ for 3 hours. $\mathrm{H}_{2} \mathrm{SO}_{4}$ was added as a catalyst for this reaction. Continuous stirring at 125 rpm was carried out for the extraction mixture. A thermostatically controlled water bath was used to heat the extraction mixture. This extraction process was designed in a flask with volumes two to three times those of the extraction mixtures to prevent oxygen evolution and substantial frothing during the initial stages. A vacuum filtration unit (Whatman 1, Maidstone, Kent, England) was used to remove the insoluble residue. Then, the product was subjected to washing with deionized water until the $\mathrm{pH}$ of the filtrate was neutral, followed by a drying process at 60 ${ }^{\circ} \mathrm{C}$. After that, the content of the delignified rice straw material was calculated. After the delignification process, the product was subjected to a leaching process with $110 \mathrm{~mL}$ of $5 \% \mathrm{KOH}$ at room temperature for 24 hours and then at $90{ }^{\circ} \mathrm{C}$ for 2 hours to remove hemicelluloses and silica. Then, the vacuum filtration process was carried out to remove the insoluble residue. The process was followed by washing with deionized water until the $\mathrm{pH}$ of the filtrate was neutral, and then it was oven-dried to remove water. Finally, the dry weight of the extracted cellulose was measured and calculated. The same methodology was followed for all four types of rice straw varieties in triplicate.

\section{Characterization of extracted materials Optical microscopy}

An optical microscope (MT, Meiji Techno Co. Ltd., Japan), at 50x magnification, was used to observe the particle size of the rice straw powder samples. Image processing software was used to analyze the particle size distribution of rice straw powder for each variety. The obtained data were statistically analyzed by Math Lab software.

\section{Thermal analysis}

Thermal analysis was performed with about $5 \mathrm{mg}$ of rice straw samples, using an SDT Q600 simultaneous thermal analyzer (TA instruments, Delaware, USA) and a heating rate of $10{ }^{\circ} \mathrm{C} / \mathrm{min}$, from ambient temperature to $600{ }^{\circ} \mathrm{C}$, under high purity nitrogen atmosphere.

\section{Fourier transform infrared spectroscopy (FTIR)}

The samples were mixed with $\operatorname{KBr}(1: 100$ w/w) and pressed into pellets. FTIR spectroscopic analysis was performed using a Bruker ALPHA spectrometer (Bruker Corporation, Billerica, MA) under ambient conditions. The spectra were recorded in the transmittance mode, running 128 scans at $4 \mathrm{~cm}^{-1}$ resolution over the $4000-600 \mathrm{~cm}^{-1}$ range. This analysis was used to confirm the complete removal of noncellulosic materials and the quality of the extracted cellulose from the four rice straw varieties.

\section{Scanning electron microscopy (SEM)}

A scanning electron microscope (EVO 18, Carl Zeiss AG, Germany) was used to examine the microstructural features and surface morphologies of the extracted cellulose materials from locally available rice straw varieties. The test samples were placed on aluminum stubs, fixed with conductive carbon tape and sputtered with gold under vacuum at $10 \mathrm{~mA}$ for 90 seconds (Sc7620 sputter coating system). The samples were observed and imaged at $14.5 \mathrm{~mm}$ working distance and $20 \mathrm{kV}$ accelerating voltage.

\section{RESULTS AND DISCUSSION}

\section{Particle size distribution of rice straw varieties}

All four varieties of rice straws were subjected to the same mechanical grinding procedure and the powders obtained were studied using optical microscopes. This method involved spreading rice straw powder on a glass slide randomly to obtain a very thin layer of rice straw powder, followed by optical microscopy imaging.

These micrographs were analyzed using Image J image processing software, to obtain the particle size distribution for each rice straw variety, assuming that particle size is proportional to the projected area of the particles. Particle size distributions were fitted to a log normal curve using the Math Lab software. The mean values of particle sizes obtained for BG300, BG352, Suwandel and Ratthal varieties are 345.7 \pm 9.1 ,

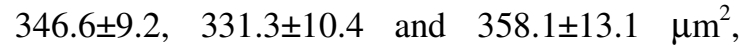
respectively (Fig. 1).

\section{Slow pyrolysis behavior of rice straw}

The presence of two distinguishable stages of rice straw slow pyrolysis can be identified by the visual observation of the DTG thermograms. These two stages of slow pyrolysis of rice straw are illustrated in Figure 2 for the BG300 rice straw variety. These two stages can be elucidated as follows.

\section{Stage I: Drying}

Rice straw is hygroscopic. ${ }^{29}$ Therefore, during this stage, evaporation of loose surface-bound water and inter-molecularly $\mathrm{H}$-bonded water can be observed. Loss of light volatiles (wax - Stage I) also takes place during this stage. ${ }^{10,12,30}$ Generally, this stage runs up to $120^{\circ} \mathrm{C}$.

\section{Stage II: Volatilization}

This stage involves the release of major amounts of volatiles from cellulose and hemicelluloses, as well as small amounts of 
volatiles from the lignin. Usually, these changes take place at temperatures above $180^{\circ} \mathrm{C}$. From the DTG thermogram, it can be observed that volatilization consists of two visible steps, and a flat tailing section. The lower temperature shoulder represents the decomposition of

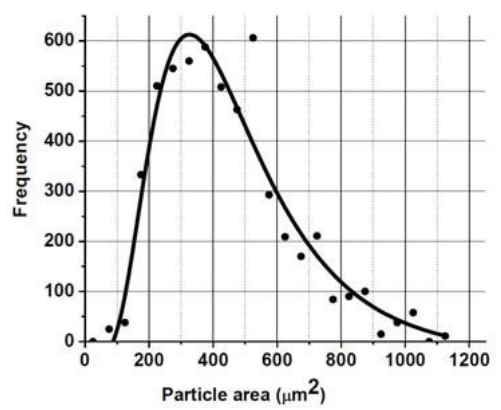

(a)

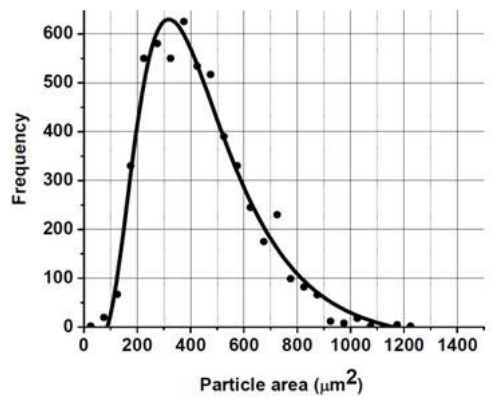

(c) hemicelluloses, while the higher temperature peak indicates the decomposition of cellulose. The flat tailing section at higher temperatures of the DTG thermogram corresponds to the degradation of lignin.

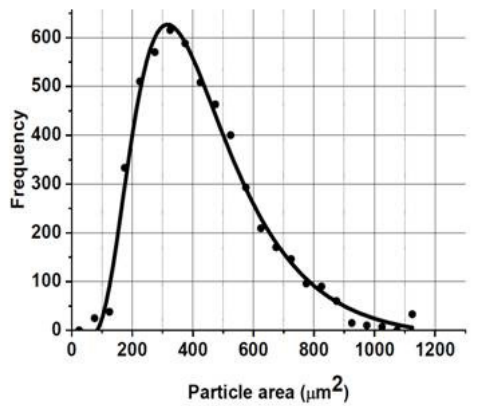

(b)

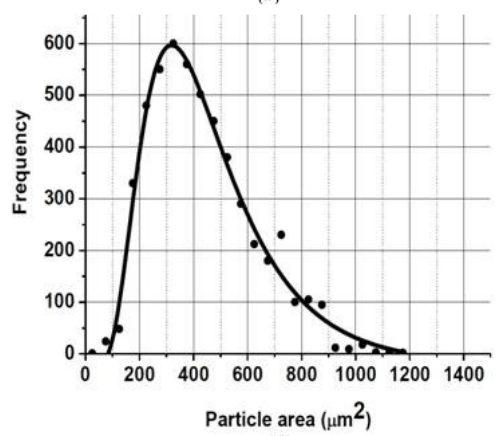

Figure 1: Particle area distribution of rice straw varieties BG 300 (a), BG 352 (b), Raththal (c) and Suwandel (d)

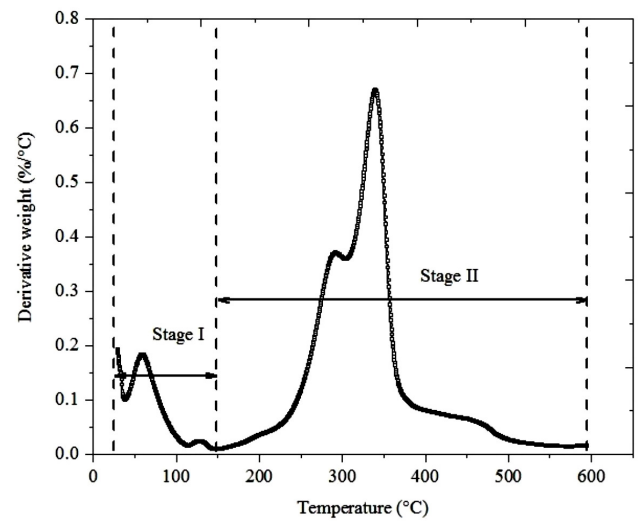

Figure 2: Stages of slow pyrolysis of rice straw for BG 300

Lignin is generally known to decompose slowly in a wide temperature range. ${ }^{31,32}$ Moreover, melting of small amounts of extractives present in rice straw (wax - Stage II) also takes place during this stage.
Determination of chemical composition of rice straw

Principle

For a sample of rice straw, the mass loss with rising temperature can be expressed as: 
$\frac{d m}{d T}=\left(\frac{d m}{d t}\right)\left(\frac{d t}{d T}\right)$

where $m$ is the percentage mass of the sample (relative to initial mass), $T$ and t are temperature and time, respectively.

Pyrolysis was carried out at a constant temperature $\operatorname{ramp}\left(d T / d t=\beta=10{ }^{\circ} \mathrm{C} \mathrm{min}^{-1}\right)$. This means each peak corresponds to a maximum rate of mass loss. It is reasonable to assume that different pyrolysis processes (or pyrolysis of different components) will have a different maximum rate of mass losses. To be more precise, the mass loss temperature profile of the constituents is more likely to be different.

The proposed method works only if it satisfies this condition:

$\Delta m(T)_{i}=\int_{T_{1}}^{T_{2}}\left(\frac{d m}{d T}\right)_{i} d T$

The above equation describes the mass loss of $i^{\text {th }}$ component with the time.

The total mass loss with the time, within the $T_{1}-T_{2}$ temperature window, is given by the following expression (Eq. (3)):

$\Delta m(T)_{\text {rample }}=\sum_{i=1}^{n} \Delta m_{i}=\sum_{i=1}^{n} \int_{T_{1}}^{T_{n}}\left(\frac{d m}{d T}\right)_{i} d T$

For any well-behaved function,

$\frac{d}{d T} m(T)_{\text {sample }}=\frac{d}{d T} \sum_{i=1}^{n} \int_{T_{m}}^{T_{m}}\left(\frac{d m}{d T}\right)_{i} d T$

This means that the sum of the DTG variations of each component is equal to the DTG signal obtained for the sample:

$$
\frac{d}{d T} m(T)_{\text {sample }}=\sum_{i=1}^{n}\left(\frac{d m}{d T}\right)_{i}
$$

Therefore, according to Equation (5), if the derivative thermograms (DTG) can be decomposed into pyrolysis processes of constituents, then, the fraction of each constituent present in the rice straw can be evaluated by the area under the corresponding deconvoluted curve, as suggested by Equation (2).

\section{Data analysis}

The predominant constituents in rice straw biomass are cellulose, hemicelluloses, and lignin. ${ }^{33}$ In addition to that, rice straw consists of epicuticular wax, which functions as a protective layer on the plant surface. ${ }^{34}$ The water-absorbing nature of rice straw also allows for the presence of minor amounts of free water and chemically bound water. ${ }^{35}$

After gaining a thorough understanding of the pyrolysis behavior of each major constituent, the DTG thermograms can be deconvoluted with the use of mathematical software, such as MATLAB. To achieve more realistic results, the non-linear least squares refinement with constraints (NLLSRC) approach was employed. As per Equation (5), when the DTG signal is broken down into the DTG signals of the constituents, the percentage of each constituent present in rice straw can be estimated by using Equation (2). The NLLSRC fitting procedure for decomposing DTG thermograms is illustrated by taking the DTG thermograms of the BG 300 variety displayed in Figure 3a. The deconvoluted DTG thermograms of BG352, Suwandel and Raththal varieties are also given in Figure 3.

The most direct information that can be acquired from this analysis is the chemical composition of rice straw. This can be attributed to the presence of three distinctive peaks in the DTG thermogram, corresponding to the degradation of hemicelluloses, cellulose and lignin in the temperature ranges of $200-400{ }^{\circ} \mathrm{C}$, 250-400 ${ }^{\circ} \mathrm{C}$ and $100-600{ }^{\circ} \mathrm{C}$, respectively. ${ }^{36}$ Moreover, this study paved the way to estimating the percentage of additional constituents in rice straw varieties through interpreting their complicated pyrolysis behavior. Wax in rice straw is a complex mixture of different constituents, which melt over a wide temperature range. Certain constituents, namely, triacontanal $\left(87^{\circ} \mathrm{C}\right)$, 1-dotriacontanal $\left(96^{\circ} \mathrm{C}\right)$ melt in the temperature range of $50-100{ }^{\circ} \mathrm{C}$, while others, such as stigmasterol (160-164 $\left.{ }^{\circ} \mathrm{C}\right)$, campesterol (150-155 ${ }^{\circ} \mathrm{C}$ ) and spinasterol $\left(171-173{ }^{\circ} \mathrm{C}\right)$ melt over the temperature range of $150-300{ }^{\circ} \mathrm{C} .{ }^{37}$ Therefore, two stages of wax melting were identified, and computation was carried out accordingly. Free water and bound water percentages were also estimated as free water and bound water evaporation was found to occur around the temperature ranges of $50-90{ }^{\circ} \mathrm{C}$ and $120-130{ }^{\circ} \mathrm{C}$, respectively. The chemical compositions predicted from the thermogravimetric analysis are summarized in Table 1. The high standard deviations are partially caused by the natural variation of compositions of paddy plants.

\section{Validation of the proposed method}

Cellulose was isolated from the chosen rice straw varieties through the three-step chemical purification process, as described in the literature. $^{40-42}$ The resultant white product obtained after this purification process was cellulose, and it was confirmed by FTIR spectra. The spectra also clearly show the sequential and complete removal of lignin, $\left(1516 \mathrm{~cm}^{-1}\right.$, aromatic 


\section{MAHESHANI P. A. NANAYAKKARA et al.}

skeletal vibrations) during peracetic acid treatment. ${ }^{38}$

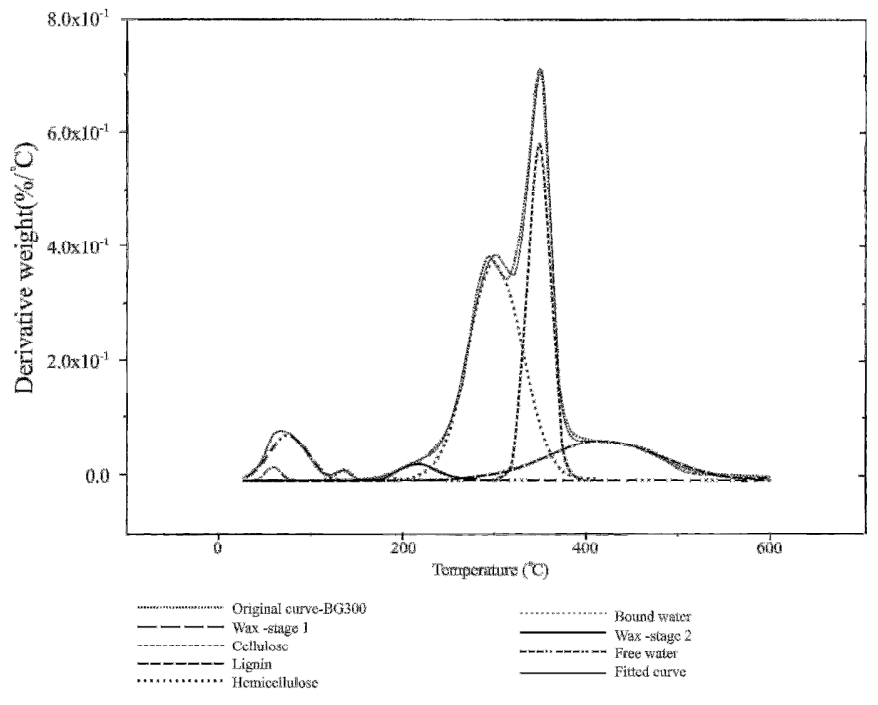

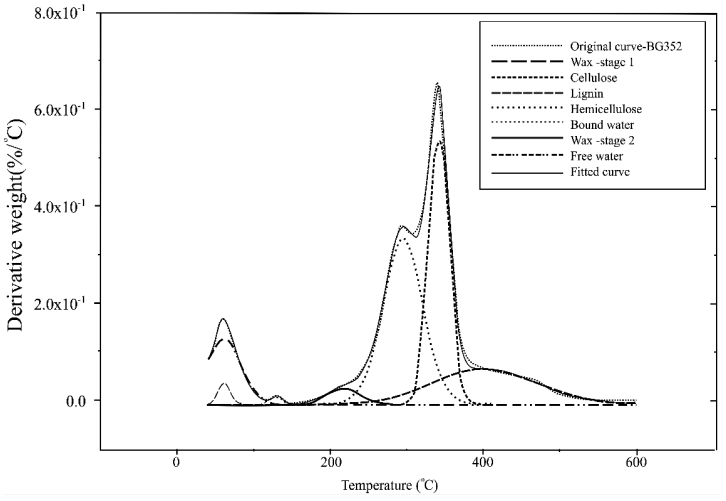

b)

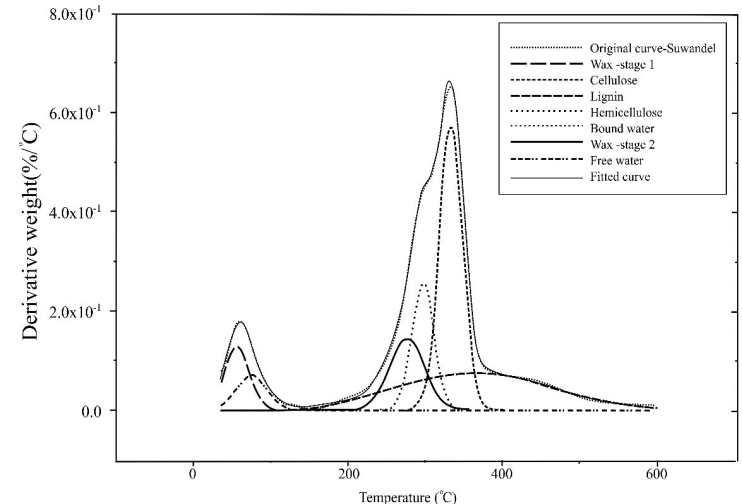

c)

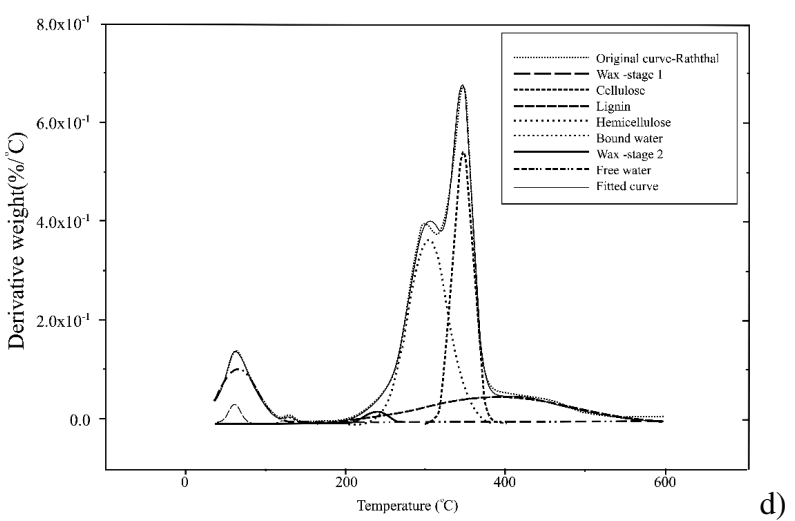

Figure 3: Deconvoluted DTG thermograms of varieties BG300 (a), BG352 (b), Suwandel (c) and Raththal (d) 
Rice straw

Table 1

Predicted chemical composition of rice straw varieties (5 TGA runs per sample was performed)

\begin{tabular}{lcccc}
\hline \multirow{2}{*}{ Constituent } & \multicolumn{4}{c}{ Rice straw variety } \\
\cline { 2 - 5 } & BG300 & BG352 & Suwandel & Raththal \\
\hline Cellulose percentage & $30.0 \pm 1.5$ & $29.5 \pm 1.4$ & $33.9 \pm 1.8$ & $28.5 \pm 1.6$ \\
Hemicellulose percentage & $44.3 \pm 2.3$ & $35.8 \pm 2.0$ & $14.1 \pm 0.9$ & $38.3 \pm 2.2$ \\
Lignin percentage & $16.9 \pm 0.8$ & $20.6 \pm 1.1$ & $28.1 \pm 1.4$ & $20.2 \pm 1.3$ \\
Wax (Stage I) percentage & $2.3 \pm 0.1$ & $2.7 \pm 0.2$ & $12.2 \pm 0.3$ & $1.5 \pm 0.2$ \\
Wax (Stage II) percentage & $0.6 \pm 0.1$ & $1.3 \pm 0.1$ & $6.6 \pm 0.3$ & $1.2 \pm 0.1$ \\
Free water percentage & $6.0 \pm 0.8$ & $9.6 \pm 0.5$ & $5.3 \pm 0.5$ & $9.0 \pm 0.6$ \\
Bound water percentage & $0.5 \pm 0.1$ & $0.4 \pm 0.1$ & $0.1 \pm 0.05$ & $0.4 \pm 0.1$ \\
\hline
\end{tabular}

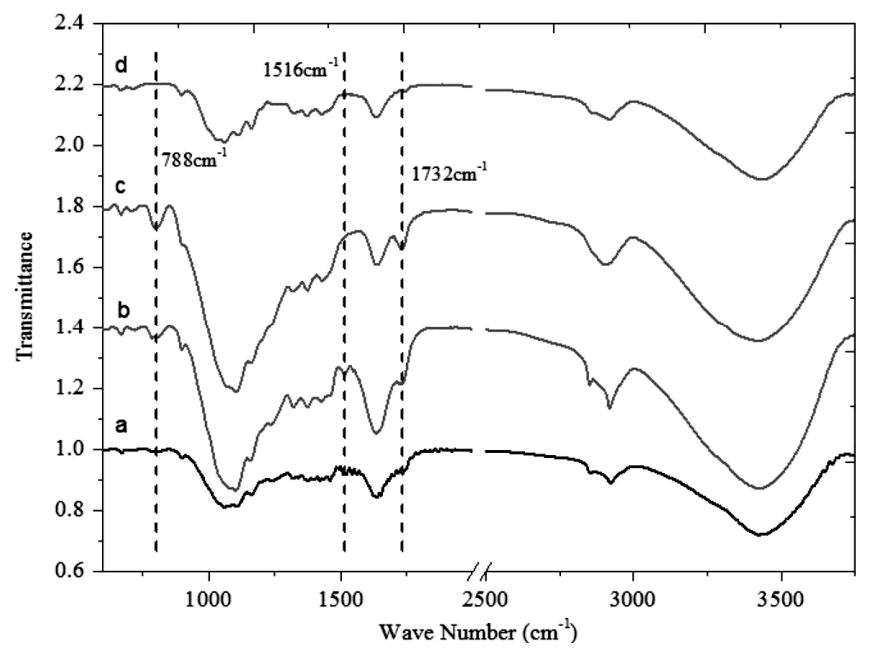

Figure 4: FTIR spectra of rice straw during chemical purification process following: (a) cleaning, (b) dewaxing, (c) delignification and (d) hemicelluloses and silica removal

It also shows the leaching of hemicelluloses (1732 $\mathrm{cm}^{-1}$, carbonyl stretching) and silica $\left(788 \mathrm{~cm}^{-1}\right.$, $\mathrm{Si}-\mathrm{O}-\mathrm{Si}$ stretching) during the alkaline treatment (Fig. 4). ${ }^{23,39}$ The results obtained by the proposed TGA method are in a very good agreement with the results obtained by the chemical isolation method. The highest cellulose yield was obtained for Suwandel variety $(35.2 \%)$. Further, the rice straw of the Raththal variety had the lowest yield of cellulose (25.1\%), while the yields from the rice straws of BG300 (27.9\%) and BG352 (29.3\%) were intermediate as per the above results.

The degree of accuracy of the TGA method was ascertained by calculating the percentage variation between predicted and experimental yields (Table 2).

Table 2

Comparison of predicted and experimental cellulose yield

\begin{tabular}{lcc}
\hline Variety & Method & Cellulose weight percentage \\
\hline \multirow{2}{*}{ BG300 } & TGA predicted & $30.0 \pm 1.5$ \\
& Chemical isolation & $28.2 \pm 1.7$ \\
\hline \multirow{2}{*}{ BG352 } & TGA predicted & $29.5 \pm 1.4$ \\
& Chemical isolation & $29.9 \pm 1.5$ \\
\hline \multirow{2}{*}{ Suwandel } & TGA predicted & $33.9 \pm 1.8$ \\
& Chemical isolation & $35.6 \pm 1.6$ \\
\hline \multirow{2}{*}{ Raththal } & TGA predicted & $28.5 \pm 1.6$ \\
& Chemical isolation & $26.4 \pm 1.5$
\end{tabular}


For all four varieties, the percentage variation was less than or equal to $5 \%$, which showed the suitability of this method to predict the cellulose yield from rice straw. However, only the predicted cellulose yield will be validated during this research. A significant variation of the chemical composition among rice straw varieties can be observed in the study. The genetic and agronomic diversity among the rice varieties selected might be the reason behind this variation. Principally, these observations predict that the highest cellulose yield could be obtained from the Suwandel variety.

\section{CONCLUSION}

The agreement between the experimentally obtained results and the predicted results based on the proposed TGA analysis (described in detail above) confirms that the three major constituents of rice straw will have different mass loss temperature profiles. Therefore, thermogravimetric analysis can be effectively utilized to predict cellulose yield of Sri Lankan rice straw varieties, with a relatively high level of accuracy. The study also shows that, among the investigated varieties, the highest cellulose yield was provided by the rice straws of Suwandel, a traditional variety. Further, this study showed that the potential of the TGA method to determine the minor constituents in the composition of rice straw.

\section{REFERENCES}

1 W. Wu, R. Shibasaki, P. Yang, H. Tan and K. Sugimoto, Sustain. Sci., 5, 29 (2010), https://doi.org/10.1007/s11625-009-0094-0

2 A. N. Siriwardene and L. N. A. C. Jayawardena, Trop. Agric. Res., 25, 437 (2014), http://doi.org/10.4038/tar.v25i3.8051

3 W. G. A. Pabasara, M. P. A. Nanayakkara, A. M. P. B. Samarasekara, D. A. S. Amarasinghe and L. Karunanayake, Trop. Agric. Res., 30, 47 (2019), http://doi.org/10.4038/tar.v30i2.8308

4 A. Ratnakumar, A. M. P. B. Samarasekara, D. A. S. Amarasinghe and L. Karunanayake, in Procs. MERCon Conference, Moratuwa, July 3, 2019, pp. 7883 ,

https://ieeexplore.ieee.org/abstract/document/8818918

5 G. Athira, A. Bahurudeen and S. Appari, J. Clean.

Prod., 236, 117598 (2019), https://doi.org/10.1016/j.jclepro.2019.07.073

6 S. Bhuvaneshwari, H. Hettiarachchi and J. N. Meegoda, Int. J. Environ. Res. Public Health, 16, 832 (2019), https://doi.org/10.3390/ijerph16050832
7 B. Gadde, S. Bonnet, C. Menke and S. Garivait, Environ. Pollut., 157, $1554 \quad$ (2009), https://doi.org/10.1016/j.envpol.2009.01.004

8 B. Xiao, X. Sun and R. Sun, Polym. Degrad. Stabil., 74, 307 (2001), https://doi.org/10.1016/S01413910(01)00163-X

A. M. P. B. Samarasekara, K. D. H. N. Kahavita, D. A. S. Amarasinghe and L. Karunanayake, in Procs. MERCon Conference, Moratuwa, May 30, 2018, pp. 449-454,

https://ieeexplore.ieee.org/abstract/document/8421934

10 W. S. M. Rathnayake, L. Karunanayake, A. M. P. B. Samarasekara and D. A. S. Amarasinghe, in Procs. MERCon Conference, Moratuwa, July 03, 2019, pp. 354-359,

https://ieeexplore.ieee.org/abstract/document/8818914

11 M. P. A. Nanayakkara, W. G. A. Pabasara, A. M. P. B. Samarasekara, D. A. S. Amarasinghe and L. Karunanayake, in Procs. MERCon Conference, Moratuwa, May 29-31, 2017, pp. 176-181, https://ieeexplore.ieee.org/document/7980477

12 W. S. M. Rathnayake, L. Karunanayake, A. M. P. B. Samarasekara and D. A. S. Amarasinghe, Cellulose, 27, 4355 (2020), https://doi.org/10.1007/s10570-02003053-5

13 A. K. Mohanty, M. Misra and L. T. Drzal, J. Polym. Environ., $\quad 10, \quad 19 \quad$ (2002), https://doi.org/10.1023/A:1021013921916

14 S. Umadaran, P. Somasuntharam and A. M. P. B. Samarasekara, in Procs. MERCon Conference, Moratuwa, April 5-6, 2016, pp. 367-372, https://ieeexplore.ieee.org/document/7480169

15 K. D. H. N. Kahawita and A. M. P. B. Samarasekara, in Procs. MERCon Conference, April 56, 2016, pp. 343-348, https://ieeexplore.ieee.org/document/7480165

16 L. D. Rajapaksha, H. A. D. Saumyadi, A. M. P. B. Samarasekara, D. A. S. Amarasinghe and L. Karunanayake, in Procs. MERCon Conference, Moratuwa, May 29-31, 2017, pp. 182-186, https://ieeexplore.ieee.org/document/7980478

17 J. M. R. Jayasinghe, A. M. P. B. Samarasekara and D. A. S. Amarasinghe, Trop. Agric. Res., 31, 21 (2020), http://doi.org/10.4038/tar.v31i2.8364

18 N. Reddy and Y. Yang, Trends Biotechnol., 23, 22 (2005), https://doi.org/10.1016/j.tibtech.2004.11.002

19 S. R. Senevirathna, S. Amarasinghe, V. Karunaratne, M. Koneswaran and L. Karunanayake, $J$. Appl. Polym. Sci., 134, 7 (2018), https://doi.org/10.1002/app.44475

20 A. M. P. B. Samarasekara, K. D. H. N. Kahavita, D. A. S. Amarasinghe and L. Karunanayake, in Procs. MERCon Conference, Moratuwa, May 30 - June 1, 2018, pp. 449-454, https://ieeexplore.ieee.org/document/8421934

21 M. Carrier, A. Loppinet-Serani, D. Denux, J.-M. Lasnier, F. Ham-Pichavant et al., Biomass Bioenerg., 35, 298 (2011), https://doi.org/10.1016/j.biombioe.2010.08.067 
22 A. G. Barneto, J. A. Armona and J. A. Conesa, Energ. Fuel., 23, $951 \quad$ (2008), https://doi.org/10.1021/ef8005806

23 P. Lu and Y. L. Hsieh, Carbohyd. Polym., 87, 564 (2012), https://doi.org/10.1016/j.carbpol.2011.08.022

24 L. Kham, Y. Le Bigot, M. Delmas and G. Avignon, Ind. Crop. Prod., 9, $21 \quad$ (2005), https://doi.org/10.1016/j.indcrop.2003.12.002

25 C. Bambaradeniya, J. Edirisinghe, D. de Silva, C. V. S. Gunatilleke, K. B. Ranawana et al., Biodivers. Conserv., $\quad \mathbf{1 3}, \quad 1715 \quad$ (2004), https://doi.org/10.1023/B:BIOC.0000029331.92656.de 26 R. Wassmann, S. V. K. Jagadish, K. Sumfleth, H. Pathak, G. Howell et al., "Advances in Agronomy", Academic Press, 2009, vol. 102, pp. 91-133, https://doi.org/10.1016/S0065-2113(09)01003-7

27 A. M. P. B. Samarasekara, M. P. A. Nanayakkara, W. G. A. Pabasara, D. A. S. Amarasinghe and L. Karunanayake, in Procs. MERCon Conference, Moratuwa, May 30, 2018, pp. 185-190, https://ieeexplore.ieee.org/document/8421949

28 A. Ratnakumar, W. S. M. Rathnayake, L. Karunanayake, A. M. P. B. Samarasekara and D. A. S. Amarasinghe, Trop. Agric. Res., 31, 106 (2020), http://doi.org/10.4038/tar.v31i3.8401

29 G. Engling, J. J. Lee, Y.-W. Tsai, S.-C. C. Lung, C. C.-K. Chou et al., Aerosol. Sci. Tech., 43, 662 (2009), https://doi.org/10.1080/02786820902825113

30 A. Ratnakumar, A. M. P. B. Samarasekara, D. A. S. Amarasinghe and L. Karunanayake, Trop. Agric. Res., 31, 72 (2020), http://doi.org/10.4038/tar.v31i3.8398

${ }^{31}$ L. F. Calvo, M. Otero, B. M. Jenkins, A. Moran and A. I. Garcia, Fuel Process. Technol., 85, 279 (2004), https://doi.org/10.1016/S0378-3820(03)002029

32 J. J. Manyà and J. Arauzo, Chem. Eng. J., 139, 549 (2008), https://doi.org/10.1016/j.cej.2007.09.005

33 P. Binod, R. Sindhu, R. R. Singhania, S. Vikram, L. Devi et al., Bioresour. Technol., 101, 4767 (2010), https://doi.org/10.1016/j.biortech.2009.10.079

34 C. Buschhaus and R. Jetter, J. Exp. Bot., 62, 841 (2011), https://doi.org/10.1093/jxb/erq366
35 L. Szcześniak, A. Rachocki and J. Tritt-Goc, Cellulose, $\quad \mathbf{1 5}, \quad 445 \quad$ (2008), https://doi.org/10.1007/s10570-007-9192-2

36 C. Song, H. Hu, S. Zhu, G. Wang and G. Chen, Energ. Fuel, 18, 90 (2004), https://doi.org/10.1021/ef0300141

37 W. Zhao, Z.-M. Zong, J. Lin, Y.-M. Song, X.-F. Guo et al., Energ. Fuel, 21, 1165 (2007), https://doi.org/10.1021/ef0602291

38 K. K. Pandey, J. Appl. Polym. Sci., 71, 1969 (1999), $\quad$ https://doi.org/10.1002/(SICI)10974628(19990321)71:12<1969::AID-APP6>3.0.CO;2-D

39 X. Colom, F. Carrillo, F. Nogués and P. Garriga, Polym. Degrad. Stabil., 80, 543 (2003), https://doi.org/10.1016/S0141-3910(03)00051-X

40 P. Lu and Y.-L. Hsieh, Carbohyd. Polym., 87, 564 (2012), https://doi.org/10.1016/j.carbpol.2011.08.022

41 A. Kumar, Y. S. Negi, V. Choudhary and N. K. Bhardwaj, J. Mater. Phys. Chem., 2, 1 (2014), https://doi.org/10.12691/jmpc-2-1-1

${ }^{42}$ K. Xu, C. Liu, K. Kang, Z. Zheng, S. Wang et al., Compos. Sci. Technol., 154, 8 (2018), https://doi.org/10.1016/j.compscitech.2017.10.022 